\title{
El aporte del derecho internacional en la fundamentación de los Derechos Humanos ${ }^{1}$
}

\author{
https://doi.org/10.21830/9789585287884.01
}

\author{
Manuel Bermúdez-Tapia ${ }^{2}$ \\ Universidad Privada San Juan Bautista \\ Paola Alexandra Sierra-Zamora ${ }^{3}$ \\ Escuela de Aviación del Ejército
}

\section{Resumen}

Este capítulo analiza la relación que surge entre el derecho internacional y los Derechos Humanos, dos referentes normativos fundamentales en el contexto contemporáneo que son interdependientes y complementarios. El alcance de esta interacción incide en el ámbito normativo, jurisdiccional y político en los Estados, particularmente para los latinoamericanos debido al impacto que ha generado el Sistema Interamericano de Derechos Humanos con la Corte Interamericana de Derechos Humanos. En este sentido, el derecho constitucional, el derecho procesal, el derecho penal, el derecho procesal penal, el derecho de familia, el derecho civil y el derecho laboral, en cuanto especialidades autónomas, han sido influidos por el desarrollo del derecho convencional, que fue materializado por la acción soberana de los Estados Americanos en 1969 con la Convención Americana de Derechos Humanos. Para analizar esta relación entre el derecho internacional y los Derechos Humanos se sigue una metodología histórico-sistemática que fundamenta una investigación cualitativa de tipo analítico. Los resultados del estudio evidencian que no solo han mejorado los contenidos sustantivos y procesales en las legislaciones nacionales,

1 Este capítulo forma parte de los resultados del proyecto de investigación "Perspectivas en Derechos Humanos y Derecho Internacional Humanitario para el Ejército Nacional de Colombia", del grupo de investigación en Aviación Militar de la Escuela de Aviación del Ejército, registrado con el código COL0077618 y categorizado en $\mathrm{C}$ por Minciencias. Los puntos de vista y los resultados de este capítulo pertenecen a los autores y no reflejan necesariamente los de las instituciones participantes.

2 Abogado de la Pontificia Universidad Católica del Perú. Magíster en Derecho. Doctorado en Derecho de la Pontificia Universidad Católica de Argentina. Profesor investigador de la Universidad Privada San Juan Bautista y profesor de la Facultad de Derecho de la Universidad Nacional Mayor de San Marcos, Lima, Perú. ORCID: https://orcid.org/0000-0003-1576-9464.Contacto: manuel.bermudez@upsjb.edu.pe.

3 Abogada de la Universidad Católica de Colombia. Magíster en Derechos Humanos, Democracia y Justicia Internacional de la Universitat de València, Espańa. Doctorado (en curso) del Programa de Derechos Humanos, Democracia y Justicia Internacional de la Universitat de València, Espańa. Investigadora de la Escuela de Aviación del Ejército, Bogotá, D. C., Colombia. ORCID: https://orcid.org/0000-0002-3146-7418. Contacto: paolasierrazamora@cedoc.edu.co. 
sino que además se ha generado una mejor esfera de acción de los límites del poder del Estado respecto de su relación con la población, que si bien le otorga legitimidad, también es mucho más consecuente con su origen histórico y político, por cuanto se debe a sus ciudadanos. La principal conclusión del trabajo es que estos avances surgieron en el derecho internacional.

Palabras clave: derecho convencional; Derechos Humanos; diálogo judicial; sistema jurisdiccional de protección de los Derechos Humanos; órganos judiciales internos; derecho internacional; tutela de los Derechos Humanos.

\section{Introducción}

Los Derechos Humanos constituyen un aporte histórico, sociológico, jurídico y cultural en el mundo que permite evaluar el ámbito de los derechos de una persona en particular respecto del Estado del que forma parte. Sin embargo, el fundamento de los Derechos Humanos no parte de la evaluación autónoma y particular de los derechos de los ciudadanos, sino que los Estados han asumido la defensa de estos derechos a través de sus propios mecanismos de materialización del poder constituyente, para lo cual han creado sistemas normativos, como ocurrió en Inglaterra, o Constituciones, como en los Estados Unidos y en América Latina. Precisamente, esta investigación analiza la importancia del derecho internacional sobre el derecho interno en este panorama constitucional nacional.

El derecho internacional ha tenido una gran influencia desde antes de que la humanidad diera el paso decisivo entre la edad moderna y la edad contemporánea, de tal manera que sus normas, en cualquier categoría jurídica, han tenido diversos efectos en los sistemas jurídicos de todos los países. Por esta razón, es necesario diferenciar el derecho constitucional de los Derechos Humanos y el Derecho Internacional de los Derechos Humanos, pues el nivel de conceptualización resulta muy similar.

Por una parte, el derecho constitucional de los Derechos Humanos parte del contenido material de las Constituciones de Querétaro y Weimar, creadas en el periodo de entre guerras. Estas Constituciones establecieron la importancia de los derechos y de las "garantías sociales" (Andrews, 2017), los cuales aportaron el fundamento filosófico y social del constitucionalismo social que originó el "Estado de bienestar" (Carbonell et al., 2002, p. 143). Precisamente, mucho antes del Pacto Internacional de Derechos Económicos, Sociales y Culturales de 1966, los derechos económicos y sociales que protegieron estas Constituciones definieron el contexto jurídico que relaciona la "persona" como ciudadano de un país y el "Estado", una relación que se basa en el contrato social ideado según los postulados de Locke y bajo 
los alcances de Hobbes (Kersting, 2001, p. 107). Desde esta perspectiva, el desarrollo de estos derechos, su naturaleza jurídica e importancia social, económica y de legitimación del poder estatal provienen del derecho constitucional y se extienden al contexto internacional.

Por otra parte, el Derecho Internacional de los Derechos Humanos surgió a finales de la Segunda Guerra Mundial debido a los elevados niveles de violencia que las acciones de los nazis y el imperio japonés habían generado. De este modo se definió un nuevo ámbito sustantivo y procesal en las relaciones internacionales con estas características:

1. El concepto de "persona”, sobre el cual se configuró el metaprincipio filosófico y político (Suárez, 2006, p. 83) de la dignidad de la persona humana, que se desarrolló en la Declaración Universal de los Derechos Humanos de 1948.

2. La prohibición del "genocidio", práctica que había sido constante a lo largo de la historia cuando se presentaban relaciones conflictivas entre dos pueblos. Cuando finalizó la Segunda Guerra Mundial, los procesos de Núremberg y Tokio establecieron un límite material al genocidio, de tal manera que se prohibieron estos actos como un elemento propio del Derecho Internacional de los Derechos Humanos (Marcano, 2005, p. 25).

3. La necesidad e importancia de tener un orden legítimo en el ámbito internacional que impone a todos los Estados la garantía de que las condiciones para superar las relaciones diplomáticas contradictorias se basen en una legislación de carácter internacional, ratificada por cada uno de los Estados que forman parte de las Naciones Unidas.

A continuación, este análisis introductorio desarrolla esta diferenciación de conceptos, a partir de la cual se estudian las características del Derecho Internacional en relación con los Derechos Humanos.

\section{Un proceso histórico particular no secuencial, pero sí incidental}

La concepción actual de los Derechos Humanos es producto de una larga sucesión de hechos autónomos, los cuales permiten afirmar que si bien no existe un proceso uniforme o secuencial, sí hay elementos vinculados entre sí. Por tanto, los Derechos Humanos se han constituido en un fundamento jurídico novedoso e 
independiente que tiene sus raíces en diversas condiciones preexistentes, las cuales se deben estudiar de forma integrada.

En primer lugar, el origen del Estado es producto de la evolución del hombre como especie y como individuo, un proceso de transformación que llevó a la humanidad de una sociedad basada en lo místico y casi salvaje hacia lo que conocemos hoy como una civilización, basada en elementos de naturaleza política, económica, social y cultural que vinculan a las personas y al Estado.

El tránsito de una horda gregaria y nómade a una sociedad sedentaria determinó los primeros elementos que configuran el poder en una comunidad y, por lo tanto, el surgimiento de las primeras comunidades y las redes de relaciones familiares. Estas últimas constituyen las primeras formas de gobierno en un territorio y sobre las cuales se estructuraron las monarquías teológicas de Egipto, Mesopotamia y China, referencias que evidencian la vinculación de áreas interdisciplinarias en la explicación del proceso de la humanidad (Espinosa et al., 2014, p. 9).

En este contexto inicial se pueden observar los elementos comunes del derecho constitucional que prevalecen hasta la actualidad: la "persona", que forma el "pueblo" o "comunidad", y el "Estado", que permite detallar la interdependencia con el "pueblo", el "territorio" y la "administración pública".

En segundo lugar se debe señalar el origen del "pueblo" y la diferenciación con otros pueblos. Cuando las primeras ciudades y civilizaciones comenzaron a ser exitosas, también surgieron dos mecanismos para regular las relaciones entre los pueblos que permanecen hasta la actualidad y que inciden directamente en el análisis de los Derechos Humanos. Por una parte, nació el Derecho de Guerra, el cual evidencia que las primeras culturas se desarrollaron a partir de características comunes a los primeros homínidos, especialmente la necesidad de "buscar alimentos y recursos" (González, 1987, p. 249), así como de buscar un "sistema de protección frente a una eventual acción agresiva de otro grupo que pudiera implicar una condición extrema sobre toda la comunidad" (Bermúdez-Tapia, 2019, p. 28), que Hobbes detalló en términos filosóficos políticos como el motivo por el cual el hombre supera su "estado natural” para generar un Leviatán (Ramírez, 2010, p. 55).

Sobre el desarrollo del "pueblo" como elemento representativo de la nación que es el conjunto de la población que vive en el mismo territorio, que genera la condición de pertenencia a una comunidad con una organización estatal que brinda protección y orden en el ámbito externo e interno que configura las reglas básicas del derecho internacional.

Siguiendo este criterio, los pueblos se han identificado y excluido en una dinámica histórica que ha producido tres situaciones que caracterizan a la humanidad: las 
relaciones de cooperación, las relaciones de subordinación y los actos de exterminio. Precisamente, a partir de estos dos elementos significativos —el derecho de guerra y el derecho internacional - la humanidad comienza a valorar la importancia de las relaciones con otros pueblos y la subsistencia con base en el acceso de recursos.

En tercer lugar está el aporte de la filosofía griega, en particular porque define por primera vez en la humanidad los conceptos de ser (respecto del hombre), república, ética y justicia-equidad, con los cuales se ha configurado la civilización occidental. En cuarto lugar se encuentra la creación del derecho en la cultura romana, que decanta el desarrollo y evolución de un sistema normativo basado en las costumbres y los principios. En este proceso se da valor formal a la ley como parte de un sistema jurídico que brinda el servicio público más significativo: la justicia, la cual tenía el misticismo que actualmente también le imponen los jueces.

En quinto lugar se debe mencionar que en la Edad Media se generaron dos aportes muy significativos al desarrollo de la cultura occidental, en particular para el ámbito de los Derechos Humanos. Por una parte, nació la concepción de los Derechos Naturales, sobre la cual se desarrolló la tesis de que el "hombre es hijo de Dios" —que explica en términos sencillos por qué en esta época no existió la esclavitud-. Asimismo, con base en esta tesis se consolidó el valor del dogma y de los principios que dotaron al ser humano de derechos cuando era juzgado, especialmente en el ámbito de la jurisdicción de la iglesia Católica.

Por otra parte, también en esta época se promulgó en Inglaterra, de forma paralela y autónoma, la Carta Magna de 1215, la cual configura el primer Estado moderno y por primera vez en la humanidad se divide el poder que se configuraba en el ámbito del Estado en un territorio, estratificado solo en dos elementos: el poder del monarca, que reina pero no gobierna, y el poder del pueblo, que sí gobierna el país.

En sexto lugar se debe mencionar que con el desarrollo de la Edad Moderna, el Estado volvió a surgir como modelo político-social y adquirieron gran importancia los conceptos de nación y de Estado, que no necesariamente son equivalentes. En séptimo lugar está la Revolución Francesa y su concepto de la soberanía del pueblo, el cual hace que este momento histórico sea superior a la Independencia de los Estados Unidos y a la proclamación de su Constitución en 1787.

En octavo lugar se encuentra el desarrollo conceptual de la noción de dignidad, la prohibición y represión de todo acto de genocidio, así como la regulación de un ámbito normativo de los Derechos Humanos que sea vinculante para los Estados y que pueda ser aplicado en el contexto nacional. Este último es el origen de los Derechos Fundamentales, pues son competencia del poder constituyente, que se desarrolla autónomamente frente al contexto de la legislación internacional. 
Finalmente, en noveno lugar se debe mencionar que en la década de los años sesenta del siglo pasado se creó una normatividad que amplió el análisis de las condiciones de los grupos vulnerables o en situación de riesgo, de tal manera que se hizo necesario tutelar los derechos de aquellas personas que no eran visibles, pues la legislación nacional estableció condiciones de estratificación y que excluían derechos en función a sus categorías étnicas, sociales, de género o en función de su condición ciudadana (Bermúdez-Tapia, 2001, p. 333).

Conforme a lo expuesto, aunque no es un producto derivado de un proceso secuencial o lineal, los Derechos Humanos han generado un nuevo panorama internacional, el cual ha dotado de legitimidad y funcionalidad a los Estados contemporáneos con una nueva visión de su alcance y contenido sustancial.

\section{Un diálogo que puede incluir un contexto punitivo}

La exposición anterior sirve como marco para evaluar el alcance de los Derechos Humanos en el ámbito de las relaciones internacionales, a la vez que permite categorizar los Estados de acuerdo con dos parámetros: (1) los Estados vinculados a una jurisdicción supranacional derivada de su propia soberanía y que tiene el objeto de generar una mejor condición en el ámbito de la tutela de los derechos de las personas. De este modo, el Derecho Internacional de los Derechos Humanos ha logrado tener un alcance ejecutivo y directo cuando un Estado ejecuta una acción indebida frente a su población, de manera que la propia ley nacional puede resultar contraria a lo dispuesto en un Tratado Internacional. (2) Los Estados ajenos al Derecho Internacional de los Derechos Humanos, que se pueden subcategorizar en dos tipos de realidades políticas:

a. Los países a los cuales resulta imposible aplicar el Derecho Internacional de los Derechos Humanos, sea por el ejercicio de un poder superior en el ámbito internacional, político, económico o militar.

b. Los países que no constituyen una referencia significativa en el ámbito de las relaciones internacionales, como ocurre con los países africanos que conforman el Cuerno de África, en los cuales pueden intervenir la Organización de las Naciones Unidas (ONU) o las potencias dominantes del mundo para atender los casos de hambruna, guerra civil o caos interno.

Como se evidencia, solo algunos parámetros del contenido material de los Derechos Humanos resultan vinculantes en el ámbito internacional, y la mejor 
evidencia es que en el año 2020 aún hay países donde (1) la esclavitud no ha sido eliminada como práctica socioeconómica; (2) se considera como un patrón socioreligioso-cultural válido realizar un matrimonio con personas en una edad inferior a la de la adolescencia; (3) se pueden cercenar los órganos sexuales, en particular para condicionar la libertad y autonomía sexual de la mujer; (3) la homosexualidad es criminalizada y punible, y (4) la mujer no tiene la misma condición jurídica, social, económica o moral que un varón.

Estas situaciones constituyen un reto al Derecho Internacional de los Derechos Humanos porque implican una acción directa sobre aquellos Estados en los cuales se presentan elementos negativos que atentan contra los objetivos máximos de un orden internacional que procura salvaguardar los derechos de las personas sin importar el contexto particular que pudiera sostener un determinado país (Quintero, 2020) y sobre la cual se desarrolla en la actualidad un diálogo de jurisdicciones, que permite determinar registros de punición y de imposición de acciones a los Estados cuando son condenados por no garantizar los Derechos Humanos o el Derecho Internacional de los Derechos Humanos. Las medidas contra dichos Estados pueden involucrar desde la reforma de su Constitución (y legislación) hasta la realización de actos de reparación, que pueden incluir elementos simbólicos a favor de las víctimas o deudos para que estos puedan superar un hecho de gran impacto en sus vidas.

\section{El alcance del presente texto}

Los apartados anteriores esbozan un panorama interesante de evaluación que permite proyectar el alcance de los seis capítulos que componen esta obra, los cuales amplían el contenido del Derecho Internacional de los Derechos Humanos a partir del análisis de elementos teóricos aplicables al desarrollo de la relación del derecho internacional y de los Derechos Humanos.

\section{Conflicto de intereses}

Los autores declaran que no existe ningún potencial conflicto de interés relacionado con este capítulo ni con el contenido del libro, que son productos generados de proyectos de investigación tanto en Colombia como en Perú.

\section{Financiación}

Los autores no declaran fuente de financiamiento para la realización de este capítulo. 
20 Perspectivas en Derechos Humanos y Derecho Internacional Humanitario para el Ejército Nacional de Colombia

\section{Referencias}

Andrews, C. (Coord.) (2017). Un siglo de constitucionalismo en América Latina (1917-2017). Centro de Investigación y Docencia Económicas.

Bermúdez-Tapia, M. (2001). Categorías de ciudadanía en el Perú, por el goce de derechos fundamentales. BIRA Boletín del Instituto Riva Agüero, 28, 333-343.

Bermúdez-Tapia, M. (2019). La construcción de la legitimidad de la Paz y el poder del Estado luego de los Acuerdos de Paz en Colombia. En Cipriano Peña Chivatá (Ed.), El poder y la estrategia militar para la negociación e implementación de los Acuerdos de Paz en Colombia (pp. 25-43). Escuela Superior de Guerra "General Rafael Reyes Prieto".

Carbonell, M., Orozco, W., \& Vázquez, R. (Coord.) (2002). Estado de derecho. Concepto, fundamentos y democratización en América Latina. UNAM-Siglo XXI Editores.

Espinoza Arango, M. (2014). El poder en plural. Entre la antropología y la teoría política. Universidad de los Andes.

González Echevarría, A. (1987). La construcción teórica en antropología. Anthropos.

Kersting, W. (2001). Filosofía politica del contractualismo moderno. Universidad Autónoma Metropolitana.

Marcano Salazar, L. (2005). Fundamentos de Derecho Internacional Público. Introducción al estudio de la historia de las instituciones del Derecho Internacional Público y su impacto en las relaciones internacionales. El Nacional.

Quintero Cordero, S. P. (2020). La cooperación internacional e intervención en escenarios de posconflicto. Sello Editorial ESMIC.

Ramírez Echeverri, J. (2010). Thomas Hobbes y el Estado absoluto: del Estado de razón al Estado de terror. Universidad de Antioquia.

Suárez Molano, J. (2006). Crítica a la razón en la filosofía del siglo XX. Universidad de Antioquia. 